\title{
Classification of Dust Emission Features in Carbon Stars
}

\section{IRENE R. LITTLE-MARENIN ${ }^{1}$, GREGORY C. SLOAN ${ }^{2}$, and STEPHAN D. PRICE ${ }^{3}$}

1 Wellesley College, Wellesley MA, U.S.A.

${ }^{2}$ NASA/Ames Research Center, Moffett Field CA, U.S.A.

3 Phillips Lab., Hanscom AFB, Hanscom MA, U.S.A.

We have cross-referenced the IRAS PSC with the GCVS, searching for AGB carbon stars, and found 99 sources brighter than $28 \mathrm{Jy}$ at $12 \mu \mathrm{m}$. We have classified their LRS spectra after removing an estimated stellar contribution. The majority of our sources fall into two categories: spectra with the classic $\mathrm{SiC}$ emission feature peaking around 11.2-11.5 $\mu \mathrm{m}$ (class $\mathrm{SiC}$ ), and spectra where the $\mathrm{SiC}$ feature appears along with an additional component peaking around 8.5-9.0 $\mu \mathrm{m}$ (class $\mathrm{SiC}+$ ). In a few stars the 8.5-9 $\mu \mathrm{m}$ feature rivals or exceeds the $\mathrm{SiC}$ feature in strength (class $\mathrm{SiC}++$ ). Our sample also contains several unusual and low-contrast dust spectra which are difficult to classify. The classic SiC class contains mostly Mira variables, while the $\mathrm{SiC}+$ and $\mathrm{SiC}++$ classes contain mostly SRs and Lbs. Classic SiC sources tend to have redder [12]-[25] colors, correspondingly lower photospheric temperatures, and longer periods than $\mathrm{SiC}+$ and $\mathrm{SiC}++$ sources. The $\mathrm{SiC}$ feature appears to be superimposed on a featureless continuum most likely due to amorphous carbon or graphitic material. The $\mathrm{C} / \mathrm{O}$ ratio increases along the sequence $\mathrm{SiC} \rightarrow \mathrm{SiC}+\rightarrow \mathrm{SiC}++$ from an average of $1.07(\mathrm{SiC})$ to $1.2(\mathrm{SiC}+)$ to 1.3 $(\mathrm{SiC}++)$. If $a: \mathrm{C}-\mathrm{H}$ is the carrier of the 8-9 $\mu \mathrm{m}$ feature (Goebel et al. 1995, $A p J, 449,246)$, we suggest that this feature will strengthen with increasing $\mathrm{C} / \mathrm{O}$ ratio. We find support for this suggestion in the increasing strength of the $\mathrm{C}_{2} \mathrm{H}_{2}+\mathrm{HCN}$ absorption feature seen in the 13-15 $\mu \mathrm{m}$ region and in the spectrum of VX And, which has the strongest 8-9 $\mu \mathrm{m}$ feature and the largest $\mathrm{C} / \mathrm{O}$ ratio (1.76).

This work was supported by my friends in Washington and at Wellesley College. 